The effectiveness of teaching geometry to enhance mathematical understanding in children with Down syndrome

Cogolludo Agustín, José Ignacio*; Gil Clemente, Elena

University of Zaragoza, Zaragoza, Spain

jicogo@unizar.es

elenagil@unizar.es

Departamento de Matemáticas. Universidad de Zaragoza. Pedro Cerbuna 1250009 Zaragoza (España) 


\title{
The effectiveness of teaching geometry to enhance mathematical understanding in children with Down syndrome
}

\begin{abstract}
It is widely known that people with Down syndrome have difficulties transitioning from a basic understanding of counting and cardinality to more advanced arithmetic skills. This is commonly addressed by resorting to the mechanical use of algorithms, which hinders the acquisition of mathematical concepts. For this reason some authors have recently proposed a shift in the focus of learning from arithmetic to more fertile fields, in terms of understanding.

In this paper we claim geometry fits this profile, especially suited for initiating children with Down syndrome into mathematics. To support this we resort to historical, epistemological, and cognitive reasons: the work of Séguin and his intuition on the central role of geometry in the development of abstract thinking in the so-called idiot children, the ideas of René Thom about the role of continuum intuition in the emergence of conscious thinking, and finally the two strengths people with Down syndrome display: visual learning abilities and interest in abstract symbols.
\end{abstract}

To support these ideas we present the main findings of qualitative research on elementary mathematics teaching to a group of eight children (3 to 8) with Down syndrome in Spain. The didactic method used, naturally enhance their naïve geometrical conceptions.

Keywords: mathematics, Down syndrome, geometry, abstract thinking, mimesis, Down syndrome, intellectual disabilities.

\section{Introduction}

A number of studies have recently revealed that the difficulties with mathematics that people with Down syndrome ${ }^{1}$ face are mainly restricted to topics around handling numbers (Monari \& Benedetti, 2011; Monari \& Pellegrini, 2010). These types of difficulties are thoroughly documented in the literature, namely 1 We have chosen to use the term Down syndrome instead of Trisomy 21 throughout this article because of its wider meaning. 
advancing from an adequate counting performance and cardinality understanding (Porter, 1998; Bird \& Buckley, 2001; Abdelhameed, 2007) to more advanced arithmetic skills such as understanding place value or addition and subtraction algorithms (Buckley, 2007; Bruno, Noda, González, Moreno \& Sanabria, 2011; Bruno \& Noda, 2012). These studies show that students with Down syndrome and poor numerical skills are able to manage successfully other areas such as Algebra and Analytic Geometry if a suitable approach tailored to their needs is used.

In spite of these encouraging results, the teaching of mathematics to people with Down syndrome remains at a stand-still, with no significant progress in terms of contents, and still biased in favor of techniques and exercises focused on number recognition and rote learning procedures. This emphasis on arithmetic skills can be better understood if we consider two basic assumptions that will be questioned here.

First, a utilitarian view of mathematics is currently prevalent in our society, losing the formative aspects of the subject altogether and thereby affecting the choice of contents. The Italian mathematician Federigo Enriques (1871-1946) posed this duality as a productive interaction between formative and utilitarian values of mathematics (Enriques, 1938). Recently Faragher and Clarke have proposed a modern reformulation of this classical dilemma specifically about people with Down syndrome: "the study of mathematics for its own sake or concentrate on life skills” (Faragher \& Clarke, 2014, p. 179). Since people with Down syndrome have the need to learn mathematics in order to better function as citizens in a complex society, and to support them in this endeavor, mathematics education usually focuses on arithmetics or -in the best-case scenario- on the broader concept of numeracy (see Faragher \& Brown, 2005) But although these aspects of mathematics are undoubtedly important in order to understand the world 
quantitatively, this is not -by far- mathematics' main goal. They contribute significantly to improving communication skills as well as abilities to think, reason, and learn. Mathematics definitely offers the possibility of sharing a cultural world, which is valuable for them as human beings.

Secondly, the established belief that mathematics is a hierarchical discipline and that arithmetical skills are the foundation on which mathematics is built, justifies the large amount of time devoted to these arithmetical contents in the current curriculum. It is assumed that students will be incapable of learning more advanced mathematics if without mastering arithmetic. So, since people with Down syndrome show evident difficulties when taught arithmetics in a traditional way, they are deprived of the opportunity to be introduced to more interesting and formative areas of mathematics such as geometry, algebra, and statistics. Nevertheless, some authors have shown disagreement with this principle, hypothesizing that "mathematics can be learned better in a parallel way by people with an intellectual impairment rather than in the traditional serial way, because they seem to learn each part at a different rate” (Monari \& Benedetti, 2011, p. 539). As the French mathematician Laurent Lafforgue claims, “(for every child, the) intimacy with numbers is built [...] by means of building a network of links” (Lafforgue, 2007, p. 2, our emphasis).

Disregarding these two assumptions -the utilitarian goal of mathematics and its hierarchical structure- frees us from the need to base the learning of mathematics on the one area in which people with Down syndrome have the greatest difficulty, arithmetic. We are thus allowed to expand into more fertile fields that stimulate their cognitive strengths to achieve higher levels of mathematical understanding and thinking. As a 
result of our research we offer empirical evidence confirming that geometry is one of these fields, especially for the mathematical initiation of children with Down syndrome.

After a period of abandon of elementary geometry in school in most European countries since the nineties, currently, there is a general consensus to consider it again as especially suited to "stimulate the ability of humans to rationally explore the physical space in which they live, the figure, the physical form" (quote from the Spanish mathematician Miguel de Guzmán (1936-2004) found in Cátedra Miguel de Guzmán web page). The French mathematician René Thom (1923-2002) strenuously supported that the geometric continuum is a primordial entity inseparable from both conscious thinking and the need every human being has of knowing their surrounding world. This epistemological point of view was the basis of his attack against the wave of "new math” in schools (Thom, 1971). Besides, the common roots of geometry and arithmetic, both based upon the concepts of repetition and infinity, suggest to put forward didactical proposals that integrate arithmetic and geometry, thus giving geometry a crucial role in the understanding of the concept of numbers (Lafforgue, 2010; Millán Gasca, 2016).

We claim that people with Down syndrome share the need to know the world and the basic continuum intuition. The abstract ideas that geometry conveys from direct experience make the world more understandable for them, so it is worth developing a method to teach them geometry. Edouard Séguin (1812-1880) highlights the central role that geometry plays in the education of children affected by some intellectual disability, precisely because it helps them in the transition from notions, which are concrete thoughts extracted from reality, to ideas, which are abstract thoughts existing only in the mind. Séguin proposes exercises that help children develop a more intense mind-body 
relationship with their environment through play and mimesis (a precise description of this term is provided in page 10), and we have designed activities based on his ideas and using the materials he devised (bricks and rods) in order to foster abstract thinking (an analysis of the contributions of Séguin to the history of education is being prepared by the second author in collaboration with Ana Millán Gasca).

Finally, two features of the cognitive profile of people with Down syndrome have led us to the believe that geometry is suitable for them: the relative strength with which they process visually-presented information (Bird \& Buckley, 2001) and their particular interest in abstract symbols as a way to understand several ideas at the same time - optimizing their limited attention span - which has recently been brought to light in the literature (Zimpel, 2016). According to this evidence, there is no cognitive reason to avoid abstraction while teaching students with Down syndrome -as it is usually done-. Mathematics, especially geometry, has been specifically developed by humans to embody abstract ideas from experience. Therefore, the choice of this subject as a path to help them to a better understanding of the world could specifically enhance their areas of cognitive strength.

\section{Context and objectives of the research}

We intend to show that teaching mathematics in a way that goes beyond simply teaching procedures by rote is an essential contribution to the integral education of children with Down syndrome. Mathematics helps them build their mind, develop their reasoning, and expand their understanding of the world. Mathematics interests all children in a natural way largely due to its degree of abstraction, which poses challenges that stimulate thinking, a fundamental issue for children with an intellectual disability. 
We share with several authors (Fuson, 1988; Hughes, 1986; Donaldson, 1978; Millán Gasca, 2016) the optimism in the natural ability of children to learn mathematics if it is taught from a formative vision. This optimism was present in the 19th century pioneers in early childhood education, Johann Pestalozzi (1746-1827) and Friedrich Fröbel (1782-1852) (see Millán Gasca, 2016).

We also share the conviction of mathematical educators specialized in Down syndrome (Faragher \& Clarke, 2014; Monari, 2002, 2011) about the possibilities these children have to learn mathematics if we take into account their idiosyncrasy, their strengths and limitations and if we always set high expectations for them.

In this context, we present the preliminary results of a research for practice in progress being carried out in Spain since 2014. The goal of this research is double: first, to verify if the geometrical intuition of children with Down syndrome is actually better than their numerical intuition, and second, to propose and test a specific learning approach to geometry.

\section{Mathematical basis and didactical approach to mathematics}

The exploration of the naïve arithmetical and geometrical conceptions of the participants confirmed that children with Down syndrome seem to show more difficulties in dealing with numbers as opposed to shapes (Millán Gasca et al., 2017). This insight has led us to focus the initial proposal on geometry, adapting Monari’s idea about the need for a non-hierarchical teaching of mathematics for people with intellectual disabilities (Monari \& Benedetti, 2011). In their work with teenagers, Monari \& Benedetti developed mathematical concepts from the understanding of Algebra. We have decided to focus our teaching programme on geometry, due, among other things, to the age of the participants. 
The "primordial", undefined concepts of the modern axiomatic description of arithmetic and geometry, if considered in their historical context (Giusti, 1999; Israel, 2011; Israel \& Millán Gasca, 2012) offer a selection of didactical ideas that had already been successfully applied in the first steps in mathematics in children 4-5 years old (see Colella 2013, 2014; Schiopetti 2013. The experimental work was developed in the already mention Resarch Lab in Roma Tre University). Therefore, we paid special attention to the role of Hilbertian's (1902) undefined concepts (point, straight line, plane), relationships (congruence, lie in, lie between), and first definitions of objects and relations (angle, segment, circle, triangle, polygon, greater than...) deduced from the axioms.

The careful analysis of ancient, basic objects and relations, from a logical point of view but also considering their roots in human physical experience guided the design of productive mathematical activities well suited for children with Down syndrome who need to divide the task into smaller steps from the beginning (Bird \& Buckley, 2001).

Table 1 shows the contents developed in our proposal analytically. These contents are derived from Millán Gasca (2016)'s table of goals and contents for early childhood (ages 3 to 6 ) math education integrating arithmetic and geometry. 



\begin{tabular}{|l|l|}
\hline Basic elements (Hilbert's axiomatic) & Solid Geometry \\
Point & Cube \\
Straight line & Rectangular prism (box) \\
$\quad$ Parallel straight lines & Cone (hat) \\
Incident straight lines & Cylinder (tube) \\
Perpendicular straight lines & Sphere (ball) \\
To be between two points & \\
Segment & \\
Rotation & \\
\hline Plane geometry & Measurement \\
Triangle & Length \\
Identify and count: shape, vertices, sides & distance, height, width, perimeter \\
Quadrilateral & Area \\
Identify and count: shape, vertices, sides & Units of measurement \\
Square, rectangle, rhombus, irregular & \\
Circle & \\
Identify: circumference, centre & \\
\hline
\end{tabular}

Table 1: Geometrical contents developed.

\section{Design of the proposal}

The design of an instrument to assess already available geometrical intuition in the children in the experimental group and of a learning path in geometry were based on the didactical proposals for the first approach to mathematics developed by the Research Lab for Maths in Primary Education (Laboratorio di matematica per la formazione primaria) in Roma Tre University.

We have used teaching aids (physical materials, 2D and 3D) adapted to the cognitive profile of children with Down syndrome, without avoiding abstraction, based upon the sensorial experience as proposed by Edouard Séguin and Maria Montessori in the last century and - specifically for children with Down syndrome - recently by André Zimpel. 
Two key aspects of the proposal are: an adequate sequencing of activities-which take advantage from a network of links (Lafforgue, 2007)- and the use of mimesis (Scaramuzzo, 2010; 2013).

The research consists of five stages. Except for the last one -currently in progress- all of them are part of the second author's PhD. thesis, co-directed by the first author (University of Zaragoza, Spain) and Ana Millán Gasca (Università degli studi Roma Tre, Italy). We are going to focus on the main stages of the research (3) and (4) (results about stages (1) and (2) can be read in (Millán Gasca, Gil Clemente \& Colella, 2017).

(1) Establishment and knowledge of the initial group of children: compilation and information about their families and school contexts; about their behaviour interests, willingness to work, interaction with adults and with children, temperamentlikes, dislikes, and preferences -fantasy characters, sports and other activities-, motor ability, expression through drawing, ability of oral expression (September-November 2014).

(2) Exploration of the naïve arithmetical and geometrical conceptions: programming, implementation and evaluation of three two-hour sessions with the group of children (December 2014-January 2015). Millán Gasca (2016) has elaborated a list of naïve arithmetical and geometrical conceptions, which has revealed fruitful to guide first steps in mathematics. She calls them naïve conceptions because children acquire them through personal contact with adults and surroundings more than through formal teaching activities. It presents an analogy with the way first language is acquired according to usage-based theory (Tomasello, 2003). 
(3) First teaching stage: programming and implementation of eight two-hour sessions during a school year, with activities based in the aforementioned approach (February -May 2015). This stage was combined with a case study that helped to outline the general conclusions and that has not been included in this paper.

(4) Evaluation of the benefits of the programme in terms of the children's degree of acquisition of mathematical knowledge by children. Synthesis and conclusions (JuneDecember 2015).

(5) Designing and validating of a didactical proposal about methodology and contents for learning geometry for children with Down syndrome. This is an ongoing stage since February 2015.

\section{Types of activities}

Since children were aged 3 to 8 and had had almost no math training, the proposed activities were based upon others that had been tested successfully for the first steps in mathematics with 4 year-old children without any intellectual disabilities (Colella, 2014). They have been carried out in a dynamic way, choosing the activities by taking into account three aspects: their suitability for the mathematical contents to be taught, their connection to the fantasy story created for each session, and their adaptability to the impaired language and scarce motor skills of our participants.

Activities can be grouped into three types: (i) Activities that involve movement, sometimes rhythmic and accompanied by music. Using their bodies, children can experience the mathematical concepts we want to transmit to them. These activities do not require oral language, only simple modelling by adults, that children can easily mimic. (ii) Activities that use manipulative material, such as geometric shapes, rods or a variety of objects that exploit children's geometric intuition allowing them to touch-and 
observe. (iii) Written activities - using paper and pencil- through which the child has to reach a first level of symbolic representation, and therefore of abstraction. Activities of type (i) and (ii) worked in the representative space: visual, motor, and tactile (Poincaré, 1902). Activities of type (iii) introduce children to the abstract geometric space.

\section{Mimesis as a didactical tool}

When designing these activities, three features of children with Down syndrome participating in the programme were taken into account. First, their scarce expressive language -some of them were yet unable to speak, while others were only able to build simple sentences- which impaired the creation of a conversation environment or math talk (Hufferd-Ackles, Fuson \& Sherin, 2004). Second, their motor delay -some of them were only beginning to walk, and most showed difficulties with coordination- which hinders the use of manipulative material and the accuracy of drawings. Finally, their

slow learning pace -they spend more time in the process of understanding and answering.

These three aspects have encouraged us to look for more suitable didactical tools in order to get a better disposition to learn and a greater degree of understanding. In this search the discovery of mimesis has been a significant development.

The use of mimesis to teach, learn, and understand has been recently explored by several researchers (Halliwell, 2002; Scaramuzzo, 2010, 2013). Mimesis is a human ability difficult to reduce to a definition and its description has its roots in the Greek classics. Aristotle in his Poetica affirms that mimesis is a way of understanding that is consubstantial to human beings, and different from rationale. According to him the words understanding, mimesis, and pleasure are closely linked. 
...(mimesis) speaks of the radical human disposition to become similar and to structure one's personality through a process of assimilation that can be totally unconscious in the subject in which it is performed (Scaramuzzo, 2013, p. 229)

Using Scaramuzzo’s words (2013, p. 322) “when the mimetic activity is done by ourselves we understand, when the mimetic activity done by others is contemplated, we also understand.” All these have a great educational relevance, leading us to reconsider the role that mimesis can have in the process of teaching and learning -even mathematics, the most rational subject. A rational approach to mathematics with children can greatly complicate understanding. If in addition one is dealing with children with Down syndrome, whose oral expressive capacity is so limited, using mimesis as a form of communication can be a productive way to face the challenges. The ability of children with Down syndrome to mimic others is remarkable (Zimpel, 2016, pp. 37-38) and this may be a relatively strong point in their learning process. It should be noted that Séguin (see Séguin, 1866) already mentioned the power of personal imitation as a first step in the building of abstract ideas by children with intellectual disability.

We have used mimesis to help them to internalize mathematical concepts and to accompany them in the path from the visual, tactile, and motor-specific perception to the abstract mathematical ideas (Rachele, 2014).

First, we have tried to involve not only the mind but also the body and all the senses in a mimetic approximation (in absence of oral and written language, body movements are a crucial way to communicate with them and to be aware of their learning process). In some activities children have represented geometric objects points, straight lines, circles...- with their bodies in an exercise of deep mimesis. 
We have taken advantage of children's spontaneous play when pretending to be others in the common game of "let's pretend to be...”. All of our sessions have a story line (Christmas, The Three Little Pigs, pirates, circus, music, photographers, explorers...) that has made the children connect to the activities emotionally, in a human sense (Donaldson, 1978).

Finally teachers have made a concerted effort to communicate at a personal level with each child engaging them emotionally to motivate them. The dynamics of the mimicking process allows the teacher to know the children better so as to recognize if and when the child shows signs of having understood the concept.

\section{Methods}

The group participating in the research consists of eight children between the ages of 3 and 8 (three aged 3, two aged 5, two aged 6, and one aged 8). Six of them attend regular schools and two of them attend special schools. Although no selection process for the group was considered necessary, one could argue a sampling bias due to the fact that the families who decided to participate in the research were members of a local Down syndrome support group in Zaragoza (Spain). All the sessions have been supported by a team of five volunteer teachers specialized in the field of intellectual disability education.

Since the objective of our research is to improve the practice, it is framed around the so-called research for practice (Faragher \& Clarke, 2014). We have used a qualitative approach following the ideas of the Dutch pedagogue, Van Manen (2011), and his hermeneutical phenomenology applied to educational research. In this approach the researcher is interested in the essential meaning of the phenomena and the meaning and importance that these have. In the case of education, we try to alleviate some 
shortcomings of current pedagogical research, such as excessive theoretical abstraction, which makes it lose contact with the world of children (Ayala, 2008). This approach shares its main methods with ethnographic research: observation, reflection, and narration.

We have carried out an experiential observation (Postic \& Ketele, 1988), an observation of the experience as a whole, that is credible and transferable to similar contexts. A close observation (Van Manen, 2011) was also carried out in order to understand the significance and the impact the experience had on each one. For this purpose, all the sessions have been documented with descriptive notes (Corsaro, 2011), literal and detailed descriptions of the sessions without any subjective interpretation.

Once this description process was completed, the second method, the reflection process, could begin. Reflexive notes ${ }^{2}$ were written, based on our knowledge of children and the mathematical knowledge presented in each session. Through them our goal was to identify what Van Manen (2003) calls essential features of knowledge.

Finally, the third method used was the narration of the living experience. At the end of the process of observation and reflection, it is necessary to write a text that allows whoever reads it to deeply understand what has happened...

...develop a stimulating and evocative textual description of the actions, behaviors, intentions and human experiences as we know them in the world of life (Van Manen, 2003, p. 37).

\section{Evaluation and results}

2. These notes have to do with what Séguin called following diary (1839), useful for recording the progress of the child. It allows one to evaluate the degree of achievement of the objectives proposed, while at the same time serving as a basis for raising new challenges. 
In the final session of the workshop, an evaluation of the maturation process of children and their learning was carried out based on observation and individual assessment activities (short questions or assignments). The goal was to assess how much genuine mathematical knowledge was acquired by the children as a result of our teaching approach. Through the quantitative analysis of the results we will be able to extract general conclusions with regards to the initial goals.

In order to establish the descriptors for the assessment of the aforementioned contents, we have considered the three different levels in which we have developed them: (i) experiential, including the ability to detect them in the environment, to represent them using body and movement and to work them out using manipulative material; (ii) symbolic representation, through writing, drawing or plastic expression; and (iii) understanding or use of appropriate terminology.

Table 2 shows contents and descriptors (adapted from Millán Gasca, 2016) designed for the assesment session.

\begin{tabular}{|l|l|}
\hline Contents & Descriptors \\
\hline Point & $\begin{array}{l}\text { Able to distinguish some point in the environment. } \\
\text { Able to point at it with their finger. } \\
\text { Able to stand at a given point on the ground. } \\
\text { Able to distinguish points among other figures that have surface (circular for instance). } \\
\text { Able to draw points. }\end{array}$ \\
\hline Straight line & $\begin{array}{l}\text { Able to distinguish straight lines in the environment. } \\
\text { Able to walk on straight lines drawn on the ground. } \\
\text { Walk in a straight line from one point to another previously defined. } \\
\text { Able to join two points on a sheet of paper with the drawing of a straight line. }\end{array}$ \\
$\begin{array}{ll}\text { Able to name a straight line when shown. } \\
\text { Able to distinguish straight lines if they are shown between several lines, some } \\
\text { of them curves. }\end{array}$ \\
\hline Relative position of two straight lines & $\begin{array}{l}\text { Able to see the intersection between two straight lines in their environment. } \\
\text { Able to draw a straight line that intersects another one that is previously drawn. } \\
\text { Able to point at the intersection between two straight drawn lines. } \\
\text { Able to see the intersection between two straight lines when drawn. }\end{array}$ \\
\hline $\begin{array}{l}\text { To be between two points (primitive } \\
\text { relationship) }\end{array}$ & $\begin{array}{l}\text { Able to stand between two objects of the environment. } \\
\text { Able to indicate on a sheet of paper, objects that are between two indicated ones. } \\
\text { Able to distinguish the object lying between two other drawn objects. }\end{array}$ \\
\hline
\end{tabular}




\begin{tabular}{|c|c|}
\hline Triangle and quadrilateral & $\begin{array}{l}\text { Able to distinguish them in the environment. } \\
\text { Able to go around its sides and count them. } \\
\text { Able to stand on its vertices and to count them. } \\
\text { Able to express the number of sides and corners of these polygons in the environment. } \\
\text { Able to draw these polygons, with a model /without a model. } \\
\text { Able to count sides and vertices of these polygons on a drawing. } \\
\text { Able to recognize these polygons between several planar shapes. } \\
\text { Able to pronounce the right words for naming them and their elements. }\end{array}$ \\
\hline Circle & $\begin{array}{l}\text { Able to distinguish circles in their environment. } \\
\text { Able to stand in the center of a circle of the environment /drawn. } \\
\text { Able to walk the perimeter of a circle. } \\
\text { Able to draw circles with /without a model. } \\
\text { Able to recognize the circles among several planar shapes. } \\
\text { Knows and pronounces the word circle }\end{array}$ \\
\hline $\begin{array}{l}\text { Solid bodies: sphere, cyllinder, cone, } \\
\text { parallelepiped }\end{array}$ & $\begin{array}{l}\text { Able to recognize these figures in their environment. } \\
\text { Able to group objects according to their shape. } \\
\text { Knows and pronounces an appropriate word for these solid bodies. }\end{array}$ \\
\hline Comparison among magnitudes & $\begin{array}{l}\text { Able to order objects according to their length. } \\
\text { To order squares according to their surface area. } \\
\text { Able to order circles according to their surface area. } \\
\text { Able to compare the height between two people. } \\
\text { Able to superimpose objects to compare their length. } \\
\text { Able to superimpose objects to compare their surface area. } \\
\text { Able to sort lengths of objects drawn on paper. }\end{array}$ \\
\hline
\end{tabular}

Table 2. Assessed contents and descriptors.

A collection of activities was designed for assigning each descriptor with one of the following three values: 0 or not initiated -if the child was unable to achieve it- 1 or in progress -if the child needed any kind of help to achieve it- and 2 or acquired -if the child was able to reach it autonomously. This assessment is based on an idea of Monari \& Pellegrini (2010).

Tables 3 to 9 show the results obtained.

All the children in the study, even the younger ones, could understand some primitive concepts such as point and straight line. They identified points, they were able to locate them if asked, and they knew how to draw them with different degrees of accuracy. They were able to walk carefully along a straight line drawn on the floor, to spontaneously go from one point to another, along a straight line and not another type of 
path and most of them were able to draw lines intended to be straight to join two points. This initial understanding reasonably suggests that it will be possible to build other more complex concepts from these.

We have noticed that in the acquisition of these more complicated concepts and relationships there is a clear difference between the group of older children (between the ages of 6 and 8) and the group of younger children (between the ages of 3 and 5). For a more detailed analysis see (Gil Clemente, E., 2016). In spite of the fact that all of them had participated in the same workshop and had similar previous knowledge, the elder ones were able to learn more. The achievements of the group of older children allow us to have a sense of what geometrical concepts can be learnt more easily and which ones are more difficult, which is helping to develop future programming.

The children in the study were able to understand crossing points between two straight lines without much effort, how to locate themselves on them, how to draw crossing straight lines and to point at the crossing point.

It was not difficult for them to recognize planar shapes -quadrilaterals, triangles and circles- and their elements in their environment and in manipulative material, identifying them by their names. The most difficult one for them was the triangle, most likely due to the large variety of their combination of angles. The ability to count the sides and vertices of polygons differs between children. Since children with Down syndrome consider sides and vertices as common objects, this ability is directly related with their general counting skills.

All children observed use the superimposing of shapes as a way to compare magnitudes such as length and surface and to order two or three objects according to 
them. This comparison task is more difficult for them if objects to be compared are drawn and can not be superimposed.

These children also have visual skills to classify the basic geometric solids sphere, cone, cylinder and rectangular prism- by similarity, the latter being the most complicated. Recall that the mathematical term of similarity refers to objects that are rescaled from one another.

The most complicated relationship to understand even for these older children was betweenness. The activities originally proposed that involved this concept required advanced linguistic as well as motor skills and therefore they were not appropriate to validate its acquisition. For instance, simple identification of betweenness was successful when three aligned objects of their surroundings were presented. However, this identification was confusing for them when more complicated arrangements of objects were presented.

All concepts have been worked out at the triple level mentioned above. Children with DS we worked with, have demonstrated ability to understand the concepts better when allowed to use their senses to experiment, or they approach the concept with physical geometrical material. The different level of language acquisition of each child has marked their ability to designate the concepts, although as expected all had a better receptive than expressive language. Their difficulties drawing circles, quadrilaterals, triangles, or straight lines are mainly associated with their poor fine motor skills, rather than with their ability for symbolic representation.

\section{General conclusions}

The results obtained in the evaluation session about children being able to understand some mathematical concepts seem to show that the lack of progress in 
learning mathematics of children with Down syndrome has more to do with an inadequate choice of contents and with a methodology that does not take advantage of their strengths, than with a real genetic impairment related to a poor conceptual understanding and innate difficulties with abstraction.

Consequently, two ideas are reaffirmed. First of all, the need to shift the beginning of learning mathematics from arithmetic to a more fertile field such as geometry. Working with geometry in early ages can help children with Down syndrome take advantage of their strong visual intuition and their interest in abstract symbols to better understand arithmetical ideas and extend future possibilities of working with mathematics to something more than the mere application of mechanical procedures.

Second, the need to choose a didactic methodology that takes better advantage of their strengths: the proposal of tasks with human sense that engage them in challenges; the use of mimesis to help them understand in a way that involves not only mind but also body and senses; the choice of activities belonging to the visual, motor and tactile representative space that Poincaré speaks about; the connection with teachers that makes children feel safe and recognized.

Our general goal however was not only to verify that their geometrical intuition and ability to learn geometrical concepts show great potential, but the suitability of the didactical approach proposed to develop their thinking skills and thus to give them a better understanding of their surrounding world.

None of the activities carried out have been mechanical and all required a level of understanding that the children participating have shown to reach. Through them we have been able to see the development of ideas that require a certain abstraction and some sort of symbolic thinking: they have understood what a point means; they have 
been able to go from one point to another, or to join two points along a straight line, even if it was not marked; they have been able to identify plane figures or geometric solids in concrete objects of their environment, abstracting the ideal shape they have in common. All these results could confirm the previously discussed hypothesis about the power of abstract thinking in people with Down syndrome.

In this way, mathematics contributes to making their world more intelligible. A knowledge of the world in a way that goes beyond the utilitarian, including aspects that are not concrete, but that require a deeper level of understanding.

Finally the results of this research show the path for designing a complete didactical proposal that allows the development of symbolic thinking upon which abstract reasoning can be built.

\section{Ongoing work and future plans}

There have been a few geometrical concepts and relationships, proposed by Hilbert (1902) that were not developed in phase (4) of the research, but that, given the positive results achieved, we believe could also be successfully presented to children. The next stage of the research, currently in progress, is the implementation and later validation of a programme of activities, with a solid mathematical basis that would allow children with Down syndrome to achieve a deeper understanding and hence promote the development of their abstract thinking. Here we show the concepts developed thus far and we suggest where these concepts can be further investigated.

(1) Segment. Although we have worked only indirectly with it when drawing straight lines that join two points, it is necessary to study further, from the inner understanding to the concept of betweenness. 
(2) Angle. We have worked with it through some body mimesis. It is necessary to work with the classical (Euclidean) concept of angle as an amplitude and the more modern idea of angle as a portion of plane.

(3) Plane. The fact that they can draw and represent planar shapes, makes us think that they will be able to understand this primitive concept. It will be useful to understand that a straight line divides the plane into two sides, and to work with plane symmetries.

(4) Polygons. Only the simplest ones have been used for identification. Strategies such as counting vertices and sides should be used to understand the properties of polygons.

We have only worked on the identification of the basic polygons. We propose to study further this concept in two directions: identifying non-regular basic polygons or polygons with a larger number of sides. This can be done through the counting of sides and vertices.

(5) Circle. Analogously, it is necessary to study further the concept of circle and introduce children to the idea of circle as the points whose distance (radius) to the center is equal.

(6) Measurement. Since measurement is connected with numbers, we have not worked with it in the workshop reported in this paper. But we are aware that this topic can be worked on in the future thanks to the individual work done with the older children (this individual case study is the object of a forthcoming paper). Measurement is a perfect link between arithmetic and geometry and therefore it is basic in our conception of first steps in mathematics. 
(7) Solids. We are developing a programme to help children discover planar shapes as the faces of polyhedrons as well as conics through footprints and planar developments.

\section{Final remarks}

As mentioned in the Introduction, the general goal of this paper is to explore the strength of geometry to enhance mathematical understanding of people with Down syndrome, especially when initiating its study. For this, we have designed a research for practice project aimed to verify whether or not the geometrical intuition of children with Down syndrome is better than their numerical intuition. In this project we have proposed and tested a specific learning approach to geometry based on the study of primordial concepts and a methodology that uses mimesis and takes advantage of the power of sensorial experience to elaborate abstract ideas.

Along these lines we have presented the positive results of our research, which shows that geometry can be considered as an emerging field in the general education of children with Down syndrome. Therefore, this approach can help children deal with something more than replication of mechanical procedures. In a nutshell, working with geometry in a way that takes advantage of the strengths of their cognitive profile shows a great potential to develop their thinking skills. The outcome is twofold: to share with them the joy of discovering mathematics through geometry and to give them a better understanding of their surrounding world.

The evidence presented is encouraging and, even though it might benefit from validation in a bigger sample, shows the need to elaborate didactical proposals that point in this direction. 


\section{References}

Abdelhameed, H. (2007). Do children with Down Syndrome have difficulty in counting and why? International Journal of Special Education, 22(2), 129-139.

Ayala Carabajo, R. (2008). La metodología fenomenológico-hermenéutica de Max Van Manen en el campo de la investigación educativa. Posibilidades y primeras experiencias [Max Van Manen’s hermeneutic-phenomenological methodology in the field of educational research. Potentials and first experiences]. Revista de Investigación Educativa, 26 (2), 409-430.

Bird, G. \& Buckley S. (2001). Number skills for individual with Down syndrome: an overview. Portsmouth, UK: The Down syndrome Educational Trust.

Bruno, A., Noda, A., Gonzalez, C. Moreno L. \& Sanabria, H. (2011). Addition and substraction by students with Down Syndrome. International Journal of Mathematical Education in Science and Technology, 42, 13-35.

Bruno, A., \& Noda, A. (2012). Estudio de un alumno con Síndrome de Down en la comprensión del sistema decimal [Study of a student with Down Syndrome in the understanding of the decimal system]. Educación matemática en la infancia, 1(2), 5-22.

Buckley, S., \& Sacks B. (2003) Motor development for individuals with Down syndrome: an overview. Potsmouth, UK: Down Syndrome Issues and Information.

Buckley, S. (2007). Teaching numeracy. Down Syndrome Research and Practice, 12 (1), 11-14 . 
Chapman, R. \& Hesketh, L. (2001). Language, cognition and short-term memory in individuals with Down Syndrome. Down Syndrome Research and Practice 7(1), $1-7$.

Colella I. (2014). Un catalogo di attività matematica prima della scrittura [A catalog of mathematical activity before writing]. Relazione finale di tirocinio in Scienze della Formazione Primaria. Roma: Università degli Studi Roma Tre.

Corsaro, W. (2010). The sociology of childhood. Pine Froge Press

Donaldson, M. (1978). Children's minds. Londres: Croom Helm.

Enriques, F. (1938). Le matematiche nella storia e nella cultura [Mathematics in history and culture]. Bologna: Zanichelli.

Faragher, R. \& Brown, R.I. (2005). Numeracy for adults with Down syndrome: it’s a matter of quality of life. Journal of Intellectual Disability Research, 49 10, 761765.

Faragher, R. \& Clarke, B.(eds) (2014). Educating learners with Down Syndrome. New York: Routledge.

Flórez, J., Garvía, B. \& Fernández-Olaria, R. (2015). Síndrome de Down: Neurobiología, Neuropsicología, Salud Mental [Down Syndrome: Neurobiology, Neuropsychology, Mental Health]. Madrid: Fundación Iberomericana Down 21.

Fuson, K. (1988). Children's counting and concepts of number. New York: SpringerVerlag.

Hufferd-Ackles, K., Fuson, K. C., \& Sherin, M. G. (2004). Describing levels and components of a math-talk community. Journal for Research in Mathematics Education, 35 (2), 81-116. 
Gil Clemente, E. (2016). Didáctica de las matemáticas para niños con síndrome de Down a partir de una visión integrada de la aritmética y geometría elementales [Teaching mathematics for children with Down syndrome from an integrated view of elementary arithmetic and geometry]. Unpublished Ph.D. Thesis Zaragoza: Universidad de Zaragoza.

Giusti, E. (1999). Ipotesi sulla natura degli enti matematici [Hypotheses on the nature of mathematical entities]. Torino: Bollati Boringhieri.

Halliwel, S. (2002). The aesthetics of mimesis. Ancient texts and modern problems. Princeton: Princeton University Press.

Hilbert, D. (1902). The foundations of geometry. Illinois: The Open Court publishing company.

Hughes M. (1986). Children and Numbers, Difficulties in Learning Mathematics. Oxford and New York : Basil Blackwell.

Israel, G. \& Millán Gasca, A. (2012). Pensare in matemática [Think mathematics]. Bologna: Zanichelli.

Israel, G. (2011). La natura degli oggetti matematici alla luce del pensiero di Husserl [The nature of mathematical objects in light of Husserl's thinking]. GenovaMilano: Marietti.

Lafforgue, L. (2007). Le calcul à l'école primaire [Calculus in elementary school], preprint https://www.laurentlafforgue.org/textes/CalculEcolePrimaireLL.pdf

Lafforgue, L. (2010). L'importance du calcul et de la géométrie à l'école primaire [The importance of calculus and geometry in elementary school]. preprint, Journées “Trans-maître”: Instruir aujourd'hui à l'école primaire, https://www.laurentlafforgue.org/textes/ImportanceCalculGeometrie.pdf 
Millán Gasca, A. (2015). Mathematics and children's minds: The role of geometry in the European tradition from Pestalozzi to Laisant. Archives internationales d'histoire

des sciences 65(2)-175, 261-277.

Millán Gasca, A. (2016). Numeri e Forme [Numbers and shapes]. Bologna: Zanichelli.

Millán Gasca, A., Gil Clemente, E. \& Colella, I. (2017). Combining historical, foundational, and developmental insights to build children's first steps in mathematics. In Dooley, T. \& Gueudet, G. (Eds.). (2017). Proceedings of the Tenth Congress of the European Society for Research in Mathematics Education (CERME10, February 1-5, 2017), 1977-1884. Dublin, Ireland: DCU Institute of Education and ERME.

Monari Martinez, E. (2002). Learning mathematics at school...and later on. Down Syndrome News and Update 2 (1), 19-23.

Monari Martinez, E. \& Pellegrini, K. (2010). Algebra and problem-solving in Down syndrome: a study with 15 teenagers. European Journal of Special Needs Education, 25(1), 13 - 29.

Monari Martinez E. \& Benedetti, N. (2011) Learning mathematics in mainstream secondary schools: experiences of students with Down syndrome. European Journal of Special Needs Education, 26 (4), 531-540.

Poincaré, H. (1902) La science et l'hypothèse [Science and hypohesis]. Flammarion. Paris.

Porter, J. (1998). The understanding of counting in children with severe learning difficulties and nursery children. Bristish Journal of Educational Psychology, 68, 331-345. 
Postic, M. \& De Ketele, J.M. (1988). Observer les situations éducatives [Observe educational situations]. Paris: Presses Universitaires de France.

Purser, H.R.M \& Jarrold C. (2005). Impaired verbal short-term memory in Down syndrome reflects a capacity limitation rather than atypical rapid forgetting. Journal of Experimental Child Psychology, 91, 1-23.

Rachele, A. (2014) Mimesis e matematica nel mondo infantile. Esperienze di formazione tra bambini e adulti [Mimesis and mathematics in the world of children. Training experiences between children and adults], MimesisLabLaboratorio di Pedagogia dell'Espressione, http://host.uniroma3.it/laboratori/mimesislab/ri at mimesisematematica.php

Rieckmann, T. (2016). Cognitive development and mathematics en Zimpel, A., Trisomy 21: what we can learn from people with Down syndrome, Capítulo 8, 158-174. Göttingen: Vandenhoeck \& Ruprecht.

Séguin, E.

(1839) Conseils à M.O...sur léducation de son fils [Advise to M.O...on the education of his son]. Paris: J.B. Baillieère.

(1846) Traitement moral des idiots et des autres enfants arrieérés [Moral treatment of idiots and other slow children]. Paris: J.B. Baillieère.

(1866) Idiocy and its treatment by the physiological method. New York: Augustus M. Kelley.

Scaramuzzo, G.

(2010). Paideia mimesis. Attualità e urgenza di una riflessione inattuale [Paideia mimesis. Present and urgency of an inadequate reflection.] Roma: Anicia. 
(2013) Mimesis: dalla riflessione teorética alla prassi educativa [Mimesis: from a theoretical reflection to educational practice]. Studi sulla formazione, 1, 227238.

Schiopetti V. (2013), Le concezioni geometriche ingenue e la Scuola dell'Infanzia [The naive geometrical conceptions and the Primary School]. Relazione finale di tirocinio. Roma: Università degli Studi Roma Tre.

Thom R. (1971). Modern Mathematics: an educational and philosophic error? American Scientist, 59, 695-699.

Tomasello, M. (2003). Constructing a language: A usage-based theory of language acquisition. Cambridge, MA: Harvard University Press.

Van Manen, M. (2003). Investigación educativa y Experiencia vivida. Ciencia humana para una pedagogía de la acción y de la sensibilidad [Educational research and lived experience. Human science for a pedagogy of action and sensitivity]. Barcelona: Idea Books.

Wishart, J. (2001). Motivation and learning styles in young children with Down Syndrome. Down Syndrome Research and Practice, 7(2), 47-51.

Zimpel, A. (2016). Trisomy 21: what we can learn from people with Down Syndrome. Göttingen: Vandenhoeck \& Ruprecht. 


\begin{tabular}{|c|c|c|c|c|c|c|c|c|c|c|c|c|c|c|c|c|c|c|c|c|c|}
\hline \multirow[b]{3}{*}{ Age / Years Old } & \multicolumn{9}{|c|}{ POINT } & \multicolumn{12}{|c|}{ STRAIGHT LINE } \\
\hline & \multicolumn{3}{|c|}{ To distinguish points } & \multicolumn{3}{|c|}{ To locate at a point } & \multicolumn{3}{|c|}{ To draw points } & \multicolumn{3}{|c|}{$\begin{array}{c}\text { To walk along a } \\
\text { straight line drawn in } \\
\text { the floor } \\
\end{array}$} & \multicolumn{3}{|c|}{$\begin{array}{c}\text { To walk between two } \\
\text { points following a } \\
\text { straight line } \\
\end{array}$} & \multicolumn{3}{|c|}{$\begin{array}{c}\text { To draw a straight } \\
\text { line between two } \\
\text { points } \\
\end{array}$} & \multicolumn{3}{|c|}{$\begin{array}{c}\text { To distinguish } \\
\text { straight from curves } \\
\text { lines } \\
\end{array}$} \\
\hline & $3-5$ & $6-8$ & Total & $3-5$ & $6-8$ & Total & $3-5$ & $6-8$ & Total & $3-5$ & $6-8$ & Total & $3-5$ & $6-8$ & Total & $3-5$ & $6-8$ & Total & $3-5$ & $6-8$ & Total \\
\hline Achieved & 3 & 4 & 7 & 3 & 3 & 6 & 4 & 2 & 6 & 4 & 3 & 7 & 4 & 3 & 7 & 2 & 2 & 4 & 0 & 1 & 1 \\
\hline In process & 0 & 0 & $\mathbf{0}$ & 1 & 0 & 1 & 0 & 1 & 1 & 0 & 0 & $\mathbf{0}$ & 0 & 0 & $\mathbf{0}$ & 2 & 1 & 3 & 0 & 1 & 1 \\
\hline Not initiated & 0 & 0 & $\mathbf{0}$ & 0 & 0 & $\mathbf{0}$ & 0 & 0 & $\mathbf{0}$ & 0 & 0 & $\mathbf{0}$ & 0 & 0 & $\mathbf{0}$ & 0 & 0 & $\mathbf{0}$ & 4 & 1 & 5 \\
\hline
\end{tabular}

Table 3. Primitive concepts

\begin{tabular}{|c|c|c|c|c|c|c|c|c|c|c|c|c|c|c|c|c|c|c|}
\hline \multirow[b]{3}{*}{ Age / Years Old } & \multicolumn{9}{|c|}{ RELATIONSHIP POINT-STRAIGHT LINE } & \multicolumn{9}{|c|}{ BETWEENESS } \\
\hline & \multicolumn{3}{|c|}{$\begin{array}{l}\text { To stand at the } \\
\text { crossing-points of } \\
\text { two straight lines }\end{array}$} & \multicolumn{3}{|c|}{$\begin{array}{c}\text { To locate the } \\
\text { crossing-point of two } \\
\text { straight lines in a } \\
\text { paper }\end{array}$} & \multicolumn{3}{|c|}{$\begin{array}{c}\text { To draw two secants } \\
\text { straight lines }\end{array}$} & \multicolumn{3}{|c|}{$\begin{array}{c}\text { To stand between two } \\
\text { objects in a straight } \\
\text { line }\end{array}$} & \multicolumn{3}{|c|}{$\begin{array}{c}\text { To draw a point } \\
\text { between two points } \\
\text { drawn }\end{array}$} & \multicolumn{3}{|c|}{$\begin{array}{l}\text { To say which point is } \\
\text { between two points in } \\
\text { a line of four points }\end{array}$} \\
\hline & $3-5$ & $6-8$ & Total & $3-5$ & $6-8$ & Total & $3-5$ & $6-8$ & Total & $3-5$ & $6-8$ & Total & $3-5$ & $6-8$ & Total & $3-5$ & $6-8$ & Total \\
\hline Achieved & 0 & 2 & 2 & 0 & 3 & 3 & 1 & 2 & 3 & 0 & 2 & 2 & 1 & 2 & 3 & 0 & 1 & 1 \\
\hline In process & 0 & 1 & 1 & 1 & 0 & 1 & 3 & 1 & 4 & 3 & 1 & 4 & 0 & 0 & 0 & 0 & 2 & 2 \\
\hline Not initiated & 4 & 0 & 4 & 3 & 0 & 3 & 0 & 0 & 0 & 1 & 0 & 1 & 3 & 1 & 4 & 4 & 0 & 4 \\
\hline
\end{tabular}

Table 4. Primitive relationships 


\begin{tabular}{|c|c|c|c|c|c|c|c|c|c|c|c|c|c|c|c|c|c|c|}
\hline & \multicolumn{18}{|c|}{ CIRCLES } \\
\hline & \multicolumn{3}{|c|}{$\begin{array}{l}\text { To stand at } \\
\text { the centre }\end{array}$} & \multicolumn{3}{|c|}{$\begin{array}{l}\text { To walk along } \\
\text { the perimeter }\end{array}$} & \multicolumn{3}{|c|}{$\begin{array}{c}\text { To recognize } \\
\text { circular objects } \\
\end{array}$} & \multicolumn{3}{|c|}{$\begin{array}{c}\text { To draw } \\
\text { with a model }\end{array}$} & \multicolumn{3}{|c|}{$\begin{array}{c}\text { To draw } \\
\text { without a model }\end{array}$} & \multicolumn{3}{|c|}{\begin{tabular}{|c|} 
To locate \\
centre of a drawing
\end{tabular}} \\
\hline Age / Years Old & $3-5$ & $6-8$ & Total & $3-5$ & $6-8$ & Total & $3-5$ & $6-8$ & Total & $3-5$ & $6-8$ & Total & $3-5$ & $6-8$ & Total & $3-5$ & $6-8$ & Total \\
\hline Achieved & 1 & 3 & 4 & 0 & 3 & 3 & 2 & 3 & 5 & 2 & 3 & 5 & 0 & 3 & 3 & 1 & 2 & 3 \\
\hline In process & 3 & 0 & 3 & 4 & 0 & 4 & 1 & 0 & 1 & 1 & 0 & 1 & 1 & 0 & 1 & 1 & 1 & 2 \\
\hline Not initiated & 0 & 0 & 0 & 0 & 0 & 0 & 1 & 0 & 1 & 1 & 0 & 1 & 3 & 0 & 3 & 2 & 0 & 2 \\
\hline
\end{tabular}

Table 5. Plane shapes: Circle

\begin{tabular}{|c|c|c|c|c|c|c|c|c|c|c|c|c|c|c|c|c|c|c|}
\hline \multirow[b]{3}{*}{ Age / } & \multicolumn{18}{|c|}{ TRIANGLES } \\
\hline & \multicolumn{3}{|c|}{$\begin{array}{c}\text { To walk along the } \\
\text { sides }\end{array}$} & \multicolumn{3}{|c|}{ To count the sides } & \multicolumn{3}{|c|}{ To count the corners } & \multicolumn{3}{|c|}{ To draw with a model } & \multicolumn{3}{|c|}{$\begin{array}{c}\text { To draw without a } \\
\text { model }\end{array}$} & \multicolumn{3}{|c|}{$\begin{array}{c}\text { To notice triangular } \\
\text { objects }\end{array}$} \\
\hline & $3-5$ & $6-8$ & Total & $3-5$ & $6-8$ & Total & $3-5$ & $6-8$ & Total & $3-5$ & $6-8$ & Total & $3-5$ & $6-8$ & Total & $3-5$ & $6-8$ & Total \\
\hline Achieved & 1 & 3 & 4 & 1 & 2 & 3 & 2 & 2 & 4 & 0 & 3 & 3 & 0 & 2 & 2 & 1 & 1 & 2 \\
\hline In process & 3 & 0 & 3 & 0 & 1 & 1 & 1 & 0 & 1 & 3 & 0 & 3 & 3 & 0 & 3 & 2 & 2 & 4 \\
\hline Not initiated & 0 & 0 & 0 & 3 & 0 & 3 & 1 & 1 & 2 & 1 & 0 & 1 & 1 & 1 & 2 & 1 & 0 & 1 \\
\hline
\end{tabular}

Table 6. Plane shapes: triangles 


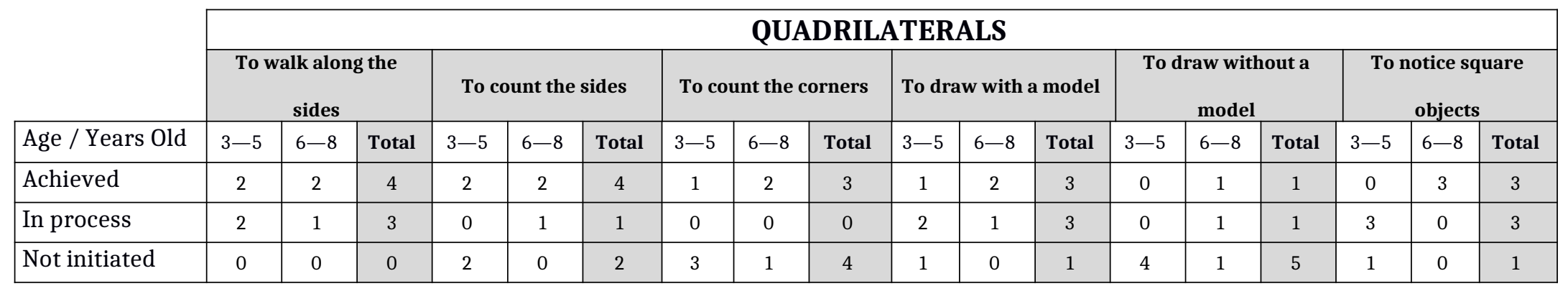

Table 7. Plane shapes: quadrilaterals 


\begin{tabular}{|l|c|c|c|c|c|c|c|c|c|c|c|c|}
\hline \multicolumn{10}{|c|}{ RECOGINITON AND SORTING OF SOLIDS } \\
\hline & \multicolumn{9}{|c|}{ Spheres } & \multicolumn{7}{c|}{ Cones } & \multicolumn{3}{|c|}{ Cylinders } & \multicolumn{3}{|c|}{ Parallelepipeds } \\
\hline Age / Years Old & $3-5$ & $6-8$ & Total & $3-5$ & $6-8$ & Total & $3-5$ & $6-8$ & Total & $3-5$ & $6-8$ & Total \\
\hline Achieved & 0 & 2 & 2 & 0 & 3 & 3 & 1 & 2 & 3 & 0 & 2 & 2 \\
\hline In process & 0 & 1 & 1 & 1 & 0 & 1 & 3 & 1 & 4 & 3 & 1 & 4 \\
\hline Not initiated & 4 & 0 & 4 & 3 & 0 & 3 & 0 & 0 & 0 & 1 & 0 & 1 \\
\hline
\end{tabular}

Table 8: Recognition and sorting of solids 


\begin{tabular}{|c|c|c|c|c|c|c|c|c|c|c|c|c|c|c|c|}
\hline \multicolumn{16}{|c|}{ COMPARISON OF MAGNITUDES } \\
\hline & \multicolumn{3}{|c|}{$\begin{array}{l}\text { To compare each } \\
\text { other's heights }\end{array}$} & \multicolumn{3}{|c|}{ To order four lengths } & \multicolumn{3}{|c|}{$\begin{array}{l}\text { To point to the tallest, } \\
\text { shortest and medium } \\
\text { size }\end{array}$} & \multicolumn{3}{|c|}{$\begin{array}{c}\text { To order squares by } \\
\text { area }\end{array}$} & \multicolumn{3}{|c|}{ To order circles by area } \\
\hline Age / Years Old & $3-5$ & $6-8$ & Total & $3-5$ & $3-5$ & $6-8$ & Total & $6-8$ & Total & $3-5$ & $6-8$ & Total & $3-5$ & $6-8$ & Total \\
\hline Achieved & 0 & 2 & 2 & 0 & 0 & 2 & 2 & 2 & 3 & 0 & 2 & 2 & 0 & 2 & 2 \\
\hline In process & 0 & 1 & 1 & 1 & 3 & 1 & 4 & 1 & 4 & 3 & 1 & 4 & 3 & 1 & 4 \\
\hline Not initiated & 4 & 0 & 4 & 3 & 1 & 0 & 1 & 0 & 0 & 1 & 0 & 1 & 1 & 0 & 1 \\
\hline
\end{tabular}

Table 9. Comparison of magnitudes 